\title{
Malaria prevention in travelling children
}

\author{
Mathijs S, MBchB, Dip(PEC), MPharmMed \\ Senior Lecturer, Department of Pharmacology, University of Pretoria, Pretoria \\ Correspondence to: Sophie Mathijs, e-mail: sophie.mathijs@up.ac.za \\ Keywords: antimalarials, chemoprophylaxis, children, insecticides, malaria
}

\begin{abstract}
Preventing malaria in children is often neglected. Prevention is very important, as malaria is still a significant cause of childhood mortality. Parents must be aware that the same measures must be taken by children to avoid being bitten by mosquitoes. Chemoprophylaxis with mefloquine, atovaquone-proguanil, doxycycline, or chloroquine is advised. The correct dose must be given, at the correct dosing interval. The choice of drug depends on several factors, such as cost, side-effects, and other drug intake. Parents must be educated on the symptoms of malaria, as making a prompt diagnosis can reduce the incidence of further complications.
\end{abstract}

(P) Peer reviewed. (Submitted: 2011-11-24. Accepted: 2012-03-01.) ๑ SAAFP

S Afr Fam Pract 2012;54(6):482-484

\section{Introduction}

Two hundred and sixteen million cases of malaria, including 655000 deaths due to malaria, were reported in 2010 worldwide. ${ }^{1}$ A child still dies every minute from malaria. In $2010,86 \%$ of malaria victims were children under five years of age. ${ }^{2}$

Thirty thousand international travellers fall ill from malaria annually. ${ }^{3}$ More and more children are travelling to malaria endemic regions, and parents still think it is unnecessary to give chemoprophylaxis. ${ }^{4}$

Humans can become infected by five species of malaria parasites after anopheles mosquito bites, namely Plasmodium falciparum, $P$. vivax, $P$. ovale, $P$. malariae and $P$. knowlesi. The most virulent form of malaria is caused by $P$. falciparum.

Children are at a very high risk of getting infected with malaria. Infants and children under five years old should avoid highrisk regions. ${ }^{5}$ However, many children do travel to malariaendemic regions. Malaria can be prevented by using the $A$, $B, C$ and D (awareness, bite avoidance, chemoprophylaxis and diagnosis) approach, as recommended by the World Health Organization (WHO). ${ }^{1}$

\section{Awareness}

Parents should be aware of the risk of malaria. Prior to travelling, they should consult their primary healthcare practitioner, to receive counselling on the measures that can be taken to prevent acquiring malaria. Advice on how to avoid being bitten and the correct chemoprophylaxis to be taken should be sought. Travellers should not be exposed to a substantial risk of adverse events from malaria chemoprophylaxis if travelling to areas where the risk of malaria infection is very low.

Parents should also be made aware of malaria symptoms. Any child who becomes ill after leaving a malaria area should be evaluated promptly.

\section{Bite avoidance}

Mosquitoes transmit malaria through bites, usually between dusk and dawn. During these times, the following measures should be taken:

- Stay indoors.

- Wear long sleeves and long pants.

- Apply insect repellent.

- Sleep under a mosquito net.

- Use mosquito coils and pads.

Insect repellents containing DEET (N,N-diethyl-metatoluamide) will protect against mosquito, fly, chigger, flea and tick bites. Insect repellents can be used safely by children who are older than two months. Do not apply to the hands, eyes, or around the mouth. ${ }^{6,7}$

Insecticide-treated nets can reduce the incidence of malaria by $50 \% .^{8}$ 


\section{Chemoprophylaxis}

No antimalarial drug is completely effective in preventing malaria. The risk of being infected with malaria should be balanced with the risk of adverse events from malaria chemoprophylaxis. ${ }^{9}$ Mefloquine, doxycycline, chloroquine, and the atovaquone-proguanil combination are recommended drugs for malaria prophylaxis. ${ }^{10,11}$

These drugs are highly effective in preventing malaria, but have shortcomings that limit their effectiveness, such as adverse effects and expense. One per cent of children stop their chemoprophylaxis due to perceived side-effects. ${ }^{4}$

Resistance of $P$. falciparum to chloroquine has been confirmed in all areas with $P$. falciparum malaria, except for the Caribbean, Central America west of the Panama Canal, and some countries in the Middle East. ${ }^{11}$ Non-compliance in children is still a problem, and needs to be addressed. ${ }^{4}$

When choosing a drug, certain factors need to be considered: ${ }^{12}$

- The child's general health and co-morbidities

- Previous exposure to antimalarial drugs

- Length of stay

- Region to be visited

- Side-effects

- Cost.

\section{Atovaquone-proguanil}

Atovaquone-proguanil (Malanil ${ }^{\circledR)}$ has been tested in numerous trials in children. ${ }^{13-15}$ It is safe and well tolerated, with few side-effects.

Paediatric tablets consisting of $62.5 \mathrm{mg}$ atovaquone and $25 \mathrm{mg}$ proguanil are available. Currently, this combination is recommended in children weighing more than $11 \mathrm{~kg}$. However, the Centers for Disease Control and Prevention (CDC) guidelines suggest that it to be safe above $5 \mathrm{~kg} .^{11}$ Malanil ${ }^{\circledR}$ is easy to use, as it is taken one to two days prior to travelling; daily while at risk; and thereafter for seven days after leaving the high-risk area. Refer to Table I for recommended dosages in children.

Table I: Dosing of Malanil ${ }^{\circledR}$ in children

\begin{tabular}{|l|l|}
\hline Weight & Dose \\
\hline $5-8 \mathrm{~kg}$ & $1 / 2$ tablet daily* \\
\hline $8-10 \mathrm{~kg}$ & $3 / 4$ tablet daily \\
\hline $10-20 \mathrm{~kg}$ & 1 tablet daily \\
\hline $21-30 \mathrm{~kg}$ & 2 tablets daily \\
\hline $31-40 \mathrm{~kg}$ & 3 tablets daily \\
\hline$>40 \mathrm{~kg}$ & 4 tablets daily, or one adult tablet ${ }^{\star *}$ \\
\hline * 1 tablet $=62.5 \mathrm{mg}$ atovaquone and 25 mg proguanil, \\
** 1 adult tablet $=250$ mg atovaquone and 100 mg proguanil
\end{tabular}

Side-effects are mild, and include nausea, vomiting, diarrhoea, abdominal pain, and mouth ulcers. ${ }^{12,16}$ If vomiting occurs within one hour of dosing, the dose must be repeated. Tablets can be mixed with food or milk, or added to chocolate spread or jam, to make them more palatable to children. The cost of this combination drug influences its choice as a chemoprophylactic agent.

\section{Mefloquine}

Mefloquine is safe for use in children weighing more than $5 \mathrm{~kg}$. It is easy to administer, as it is given once a week, starting two weeks prior to travel, and continued for four weeks after leaving the malaria endemic area.

Mefloquine has been associated with more adverse effects, which limit its use. ${ }^{9,16}$ Vivid dreams, hallucinations, and other neuropsychiatric problems have been reported. ${ }^{4}$

Administration to children is easy, as the tablets can be crushed and mixed with food or milk. Paediatric tablets are not available. Adult tablets need to be split, in order to give the correct dose. Refer to Table II for the correct dosages in children.

\section{Doxycycline}

Doxycycline may be given to children who are older than eight years of age. However, it is recommended for children over the age of 12 years. The dosage is $2.2 \mathrm{mg} / \mathrm{kg}$, up to the adult dose of $100 \mathrm{mg}$ daily. ${ }^{17}$ This should be started one to two days before entering the malaria area, and continued daily, for four weeks after leaving the high- risk area. Doxycycline is associated with photosensitivity, nausea and vomiting, abdominal pain, and oesophagitis. The sideeffects, the fact that it may affect growth of children's bones and teeth, and the long prophylaxis duration, make it a poor choice of drug for children.

\section{Chloroquine}

Chloroquine may only be used in areas in which chloroquine resistance is not present. Prophylaxis should begin two weeks prior to travel, and continue for four weeks after leaving the malaria area. Side-effects are mild, and include gastrointestinal disturbances and headaches. Chloroquine may be better tolerated if administered after a meal.

Table II: Dosing of mefloquine in children

\begin{tabular}{|l|l|}
\hline Weight & Dose \\
\hline $5-19 \mathrm{~kg}$ & $62.5 \mathrm{mg}(1 / 4 \text { tablet })^{*}$ \\
\hline $20-30 \mathrm{~kg}$ & $125 \mathrm{mg}(1 / 2$ tablet $)$ \\
\hline $31-45 \mathrm{~kg}$ & $187.5 \mathrm{mg}(3 / 4$ tablet $)$ \\
\hline$>45 \mathrm{~kg}$ & $250 \mathrm{mg}(1$ tablet $)$ \\
\hline * 1 tablet = $250 \mathrm{mg}$ adult tablet, equivalent to 228 mg base
\end{tabular}

* 1 tablet $=250 \mathrm{mg}$ adult tablet, equivalent to $228 \mathrm{mg}$ base 
Chloroquine should be taken once a week, at $5 \mathrm{mg} / \mathrm{kg}$ base (8.3 $\mathrm{mg} / \mathrm{kg}$ salt), up to a maximum adult dose of $300 \mathrm{mg}$ base. $^{11}$

\section{Diagnosis}

The majority of malaria cases are contracted in recognised high-risk malaria areas. Prompt diagnosis is critical. In a study by Waner et al, $26 \%$ of patients presented to their healthcare practitioner immediately after the onset of symptoms. ${ }^{18}$

The majority of patients waited one to five days before seeking medical attention. Few patients recognised fever and flu-like symptoms as symptoms of malaria. This indicates that better education is required for both parents and healthcare providers. Refer to Table III for the symptoms of malaria.

\section{Other agents in development}

Tafenoquine is a long-acting 8-aminoquinoline, which acts on all life stages of the malaria parasite. It appears to be safe and well tolerated, with few adverse effects. ${ }^{19}$ Tafenoquine has been used as a prophylactic agent in adults, but has yet to be tested in children.

A new malaria vaccine has been developed. Results from a phase 3 trial look promising. ${ }^{20}$ The RTS,S/ASO1vaccine reduced malaria by half in children aged 5-17 months, for 12 months after vaccination. Problems such as duration of protection and adverse effects need to be addressed, before its use can be recommended.

\section{Conclusion}

Malaria is still one of the leading causes of childhood deaths. By using the WHO A, B, C and D approach, one can reduce the incidence of malaria infections.

Compliance in children is still a major problem, and this can only be improved by educating parents. Prompt diagnosis, and having a high index of suspicion of any sick child, who has travelled to a malaria area, could save a child's life.

Table III: Symptoms of malaria

\section{Non-specific symptoms}

Fever, sweating, chills, malaise, muscle aches, headaches, diarrhoea, and coughing

\section{Severe complicated malaria}

Impaired consciousness, seizures, anaemia, hypoglycaemia, jaundice, and respiratory distress and acidosis

\section{References}

1. World malaria report, 2011. World Health Organization [homepage on the Internet]. c2012. Available from: http://www.who.int/malaria/world_malaria report_2011/en/index.html

2. Malaria deaths are down but progress remains fragile. World Health Organization [homepage on the Internet]. c2011. Available from: http://www.who.int/ mediacentre/news/releases/2011/malaria_report_20111213/en/index.html

3. The A, B, C, D of malaria protection. World Health Organization [homepage on the Internet]. c2011. Available from: http://www.who.int/malaria/travellers/en

4. Albright TA, Binns HJ, Katz BZ. Side effects of and compliance with malaria prophylaxis in children. J Travel Med. 2002;9(6):289-292.

5. Black RE, Cousens S, Johnson HL et al. Global, regional, and national causes of child mortality in 2008: a systemic analysis. Lancet. 2010;375(9730):1969-1987.

6. Fradin MS, Day JF. Comparative efficacy of insect repellents against mosquito bites. N Engl J Med. 2002;347(1):13-18.

7. McGready R, Hamilton KA, Simpson JA, et al. Safety of the insect repellent $\mathrm{N}, \mathrm{N}-$ Diethyl-M-Toluamide (DEET) in pregnancy. Am J Trop Med Hyg. 2001;65(4):285-89.

8. Lengeler C. Insecticide-treated bednets and curtains for preventing malaria. [Cochrane review]. In: The Cochrane Library, Issue 2, 2004. Oxford: Update Software.

9. Schlagenhauf $P$, Petersen E. Malaria chemoprophylaxis: strategies for risk groups. Clin Microbiol Rev. 2008;21(3):466-472.

10. Jacquerioz FA, Croft AM. Drugs for preventing malaria in travellers. [Cochrane review]. In: The Cochrane Library, Issue 4, 2009. Oxford: Update Software.

11. Choosing a drug to prevent malaria. Centers for Disease Control and Prevention [homepage on the Internet]. c2012. Available from: http://www.cdc.gov/malaria/ travelers/drugs.html

12. Lalloo DG, Hill DR. Preventing malaria in travellers. BMJ. 2008;336(7657):1362-1366.

13. Nakato $H$, Vivancos $R$, Hunter PR. A systemic review and meta-analysis of the effectiveness and safety of atovaquone-proguanil (Malarone) for chemoprophylaxis against malaria. J Antimicrob Chemother. 2007;60(5):929-936.

14. Lell $B$, Luckner $D$, Ndjané $M$, et al. Randomised placebo-controlled study of atovaquone plus proguanil for malaria prophylaxis in children. Lancet. 1998;351(9104):709-713.

15. Looareesuwan S, Chulay JD, Canfield CJ, Hutchinson DB. Malarone (atovaquone and proguanil hydrochloride): a review of its clinical development for treatment of malaria. Malarone Clinical Trials Study Group. Am J Trop Med Hyg. 1999;60(4):533-451.

16. Overbosch $D$, Schilthuis $H$, Bienzle $V$, et al. Atovaquone-proguanil versus mefloquine for malaria prophylaxis in non-immune travellers: results from a randomized, double-blind study. Clin Infect Dis. 2001;33(7):1015-1021.

17. Tan KR, Magill AJ, Parise ME, Arguin PM. Doxycycline for malaria chemoprophylaxis and treatment: report from the CDC expert meeting on malaria chemoprophylaxis. Am J Trop Med Hyg. 2011;84(4):517-531.

18. Waner S, Baker L, Wolfaardt DC, et al. Risk factors and characteristics of patients with acute Plasmodium falciparum malaria presenting to a private hospital network in South Africa. J Travel Med. 2003;10(5):296-298.

19. Nasveld PE, Edstein MD, Reid M, et al. Randomized, double blind study of the safety, tolerability, and efficacy of tafenoquine versus mefloquine for malaria prophylaxis in non-immune subjects. Antimicrob Agents Chemother. 2010;54(2):792-798.

20. Aqnandji ST, Lell B, Soulanoudjingar SS, et al. First results of phase 3 trial of RTS,S/ ASO1malaria vaccine in African children. N Engl J Med. 2011;365(20):1863-1875. 